\title{
Universals in the Visual-Kinesthetic Modality: Politeness Marking Features in Japanese Sign Language (JSL) ${ }^{1}$
}

\author{
JOHNNY GEORGE \\ The University of Tokyo
}

\section{Introduction}

This work describes results of an experiment that teases out politeness marking features in JSL. The study uncovers a number of prosodic features relevant to marking politeness in JSL, and additionally, demonstrates that non-signers and signers share a visual-kinesthetic medium of communication that enables nonsigners to occasionally interpret signs derived from assimilated gestures recognized either culturally in Japan or universally by users of different languages.

The study is based on the Hill et al. (1986) study comparing the use of polite request expressions in American English and Japanese. Consultants watched videos of twenty different expressions in which a native JSL signer makes a request for a pen and then consultants rated the degree of carefulness of each request phrase. The resulting ratings were normalized and averaged to produce a ranking of the expressions by politeness level in order to identify JSL features marking politeness.

The findings show that a number of prosodic features mark politeness in JSL including facial expression, size of signing space, head position and rate of signing. Non-signers shared similar intuitions as signers about the politeness levels of more than half the expressions. The study will refer to a view of encoded visual-kinesthetic tokens from two perspectives, culturally specific and crosslinguistic. The first designates a shared cultural code available to both Deaf and hearing people such as emblems and culturally specific coverbal gesture

\footnotetext{
${ }^{1}$ Special thanks to Sunada Atom, Ichida Tadashi, Kimura Harumi, Eve Sweetser, Sharon Inkelas, Yoko Hasegawa, Kushima Teruyuki, Tama, Sakane Ari, Kajzwara Mizuho and the National Rehabilitation Center for Persons with Disabilities (NRCPD) College. Supported by the FulbrightHays DDRA, UCB Center for Japanese Studies, and the UCB Center for Race and Gender.
} 


\section{Johnny George}

(McNeill 1992). The second refers to crosslinguistically recognizable communication cues such as facial expression (Ohala 1994). Cues related to the shared visual-kinesthetic medium used by Japanese signers and non-signers facilitated the non-signers' ability to rate politeness levels in a way consistent with the intuitions of JSL signers.

This research shows that prosody occupies a key role in marking politeness, and any investigation of politeness is incomplete without a thorough investigation of prosodic as well as lexical features. JSL relies on a number of non-manual signal features, similar to prosodic features in spoken language, to express a broad range of politeness registers. My work also shows that signers and non-signers have closely shared communicative practices evolving from their shared social context. While it has been understood that signers have access to non-signer communicative practice from the oral-aural modality, the examination of nonsigners' ability to access information from the sign modality due to shared visualkinesthetic communicative practice has not received as much consideration.

\section{$1 \quad$ Prosody}

In the modalities of sign and speaking prosody refers to a number of suprasegmental features that contribute to the meaning of a given expression. Prosody in speech designates qualities such as loudness, rhythm, speed, voice quality, stress and intonation while sign prosody includes size of signing space, rhythm, speed, holds, tenseness or laxness of movement, and non-manual signals (NMS) such as facial expression and head and mouth movement (Sandler 2006).

Prosodic correlates between signing and speaking discussed in the literature include: size of signing space to loudness of the voice (Uyechi 1996, Zimmer 1989), and head movement and facial expression, referred to as "superarticulation," to intonation (Sandler 2006).

While prosodic features such as stress, pitch accent and tone in speech and NMS can create lexical distinctions all of the prosodic features mentioned above have uses that do not involve lexical contrast. The communicative aspect of prosody has relevance to marking register. This paper focuses on prosody defined as the manipulation of the communication signal for communicative purposes rather than marking lexical distinctions.

\section{$2 \quad$ Studies on Sign Language Register and Politeness}

A number of studies discuss register variation in sign, especially contrasting the public arena with private contexts. Feature contrasts between formal and informal signing should be reflected in the same way for polite as opposed to less polite signing, since social distance makes up a component of politeness and register. Certain prosodic contrasts in signing speed, articulation, and size of signing space 
potentially represent crosslinguistic contrasts across sign languages.

\subsection{Register in Sign Language}

Cokely and Baker-Shenk (1980) posits the use of formal signing in public contexts, especially lectures and business environments, while they assume informal signing occurs in contexts where the social distance is small, such as for family members or friends at a party. The changes in signing style they predict relate to the clarity and level of articulation for the signing. Along with Liddell and Johnson (1989[1985]) they note that formal signing is more clearly articulated than informal signing while casual signing involves more deletions of the use of the non-dominant hand. Cokely and Baker-Shenk (1980) and Liddell and Johnson (1989[1985]) both note that in casual signing signs that might normally contact the forehead can contact at the cheek or in neutral space, so the signs become phonetically reduced in informal contexts. Liddell and Johnson (1989[1985]) also note more assimilation, with signs that otherwise have different handshapes becoming similar as the non-dominant hand assimilates to the shape of the dominant hand.

Studies by Zimmer (1989) and Ross and Berkowitz (2008) support the observation that in relatively more formal signing contexts signers more clearly articulate signs while using more assimilation in relatively more informal contexts. Zimmer (1989) compares video from a signer who uses ASL in three contrasting discourse contexts: a formal lecture in an academic setting, a television interview and an informal talk. Ross and Berkowitz (2008) compare videos of signers giving formal academic lectures with videos of signers giving presentations in relatively informal contexts. Both studies observe more technical vocabulary and fingerspelling in formal speech contexts with less use of colloquial vocabulary. The signs are produced more clearly and slowly in the formal contexts than in the informal contexts, supporting the need for less assimilation. They also both find a reduced use of expressive NMS in the formal contexts.

One contrast that Ross and Berkowitz expected to find that they did not in contrast to Zimmer was the use of a larger signing space. Ross and Berkowitz posited that the use of a larger signing space would add to the clarity of a sign, therefore increased signing space size would be one of the qualities of formal sign.

\subsection{Facial NMS Politeness Markers in ASL}

Hoza (2007) in an extensive study on politeness in ASL challenges the folk notion that ASL signers use more direct language than English speakers by identifying Brown and Levinson (1987) style discourse strategies in requests and refusals in 
ASL via a discourse completion test (DCT). He experimentally finds a number of NMS expressive contrasts used to mark politeness in ASL that originally were described in a study by Roush (2007 [1999]). Roush identifies NMS that mitigate severe threats to face including polite pucker and polite grimace. Hoza adds two other markers, tight lips and polite grimace frown, to Roush's inventory. The following expressions mitigate small face threats to a severe face threats: polite pucker/tight lips, polite grimace and polite grimace frown.

The consultants from the JSL pen study utilized polite grimace and polite grimace frown. In the pen study, the degree of grimace impacted consultant ratings in an apparently gradient fashion indicating that such expressions intensify the meaning of a given request.

\subsection{Head Position and Movement in JSL}

For Japanese Sign Language (JSL) Ichida (2005b) categorizes various types of head movements and positions in JSL, especially in collocations with facial NMS.

\subsubsection{Head Position}

Ichida (2005a, 2005b) discusses the semantics of head or chin position in JSL. Ichida notes that chin position is instrumental in marking the relative status of the interlocutors. The location of the chin influences the overall head position and signals and important prosodic cue. The chin position labels in the data set description in the feature chart come from Ichida (2005c). The forward chin (F) position consists of a lowering and extension of the chin away from the body. Extending the chin to a forward position slightly lowers the head. Ichida labels the forward chin in JSL as marking a closer connection to the interlocutor and associated with propositional content. The back chin position is in the opposite direction with the chin being drawn back towards the chest. The back chin can also mark propositional content, but it additionally marks the creation of distance between the signer and interlocutor indicating reserve. Ichida posits that the back chin position would occur in relatively more polite expression contexts. In all cases Ichida refers to the semantics of the positions as general tendencies subject to shift with combination with other NMS and the given language context.

\subsubsection{Head Movement in JSL}

Ichida (2005b) categorizes various types of head movements in JSL. He focuses on the relation of head movement to semantics, question formation, phrase marking and backchannelling. The two head movements associated with politeness markers from the two studies are the head nod and the head hold. The head nod tends to indicate assent, agreement or confirmation. In the head hold the head is held in place for a slight duration along with a delay of the release of its 


\section{Universals in the Visual Kinesthetic Modality}

co-occurring sign. The head hold appears with yes/no questions in JSL and in the studies it frequently appears at the end of a request along with a chin forward position. Ichida posits that the association between head holds and yes/no questions softens a given request signaling to the interlocutor that it may be refused (personal communication). The head hold tends to occur with expressions rated as more polite by pen study consultants.

\section{The Pen Request Study}

The primary aim of the pen study is to provide a description of features that mark politeness in JSL. The second aim is to consider to what extent signers and nonsigners share the same politeness system. Based on the work from the previously discussed literature on sign language politeness and register marking, the working hypothesis is that JSL relies heavily on prosody for politeness marking. Nonmanual signal (NMS) features such as facial expression, size of signing space, head position and rate of signing will mark politeness register contrasts.

Signers and non-signers share a cultural code in the visual-kinesthetic modality, and sign languages contain signs derived from this shared code; some subset of these signs can maintain enough transparency such that non-signers can intuit their meanings. The signers and non-signers share similar judgments for a number of the pen phrase tokens, so this investigation includes determining what specific features serve as meaningful cues to non-signers and to what extent such cues come from the shared visual-kinesthetic communicative space. In turn, we can have a much clearer understanding of what cues independently belong to the repertoire of sign language users.

\subsection{Procedure}

The pen study is based on the Hill et al. (1986) study comparing the use of polite request expressions in American English and Japanese. The pen study generates results based on the metrics of social distance and relative power levels of the interlocutors while controlling for the level of imposition. Each consultant watched 20 short videos in which a native signer ${ }^{2}$ makes a request for a pen in various ways. The consultants judged the degree of carefulness of each pen request expression.

I discussed the experiment with a Deaf native signer and gave him a list of the Hill et al Japanese and English pen request expressions and scenarios. The signer referred to the list of scenarios and the various Japanese and English expressions in order to generate different expressions for requesting a pen. The signer did not produce one to one interpretations but referred to the given English and Japanese

\footnotetext{
${ }^{2}$ I will use the term "native signer" to refer to signers who began their acquisition of sign language
} from birth onwards. 
material to get an idea of the range of expressions and possible contexts for creation of the tokens for the study. I then videoed the signer and used the material to create a database driven survey using all 20 tokens produced by the signer $^{3}$. All phrases produced by the signer were transcribed and annotated in Elan. Consultants watched the pen request clips and could view them as many times as desired. For each request, the consultant would rate the expression from one to five, with a rating of one meaning that the expression could be used when a person is the "least inhibited" in their expression, and the rating of five used when a person is "most careful" in their expression. The consultants could also choose "NA" for expressions that they judged as unusable; expressions assigned "NA" received a rating score of zero. Each set of consultant ratings were converted into $z$-scores so that the rankings represent the relative weight given to each token by the study consultants; so for instance, if there were an extreme case in which a consultant ranked all expressions five, then all such tokens would receive z-score ratings of zero since impressionistically no expression was more or less different in register than others for that given consultant. The use of z-scores allows for better comparison among all respondents and between signer and non-signer respondents.

\subsection{The Subjects}

20 JSL signers and 15 non-sign language users completed the survey. All signers identified as Deaf with five of those signers being native signers with Deaf parents. The tables below summarize the consultant profile data.

(1.1) Consultant Profile Summary

\begin{tabular}{|l|l|l|l|l|l|l|l|l|l|l|}
\hline All Consultants & n & \multicolumn{4}{l|}{ sex } & \multicolumn{4}{l|}{ age } & \multicolumn{2}{l|}{ occupation } \\
\hline & n & f & m & 19 & 20 s & 30 s & 40s & 50 s & job & student \\
\hline Signers (Ro) & 20 & 12 & 8 & 0 & 2 & 8 & 8 & 2 & 18 & 2 \\
Non-signers (Cho) & 15 & 12 & 3 & 2 & 11 & 2 & 0 & 0 & 0 & 15 \\
\hline
\end{tabular}

(1.2) Deaf Consultant Profile Summary

\begin{tabular}{|c|c|c|c|c|c|c|c|c|c|c|c|c|c|c|c|}
\hline & & \multicolumn{2}{|c|}{ sex } & \multicolumn{4}{|c|}{ age } & \multicolumn{2}{|c|}{ JSL exp } & \multicolumn{6}{|c|}{ JSL acquisition start } \\
\hline Signers & $\mathrm{n}$ & $\mathrm{f}$ & $\mathrm{m}$ & $20 \mathrm{~s}$ & $30 \mathrm{~s}$ & $40 \mathrm{~s}$ & $50 \mathrm{~s}$ & $10+$ & $20+$ & 0 & 1 & 5 & el & hs & $20 \mathrm{~s}$ \\
\hline $\begin{array}{l}\text { Native } \\
\text { Fluent }\end{array}$ & \begin{tabular}{|l}
5 \\
15
\end{tabular} & $\begin{array}{l}3 \\
9\end{array}$ & $\begin{array}{l}2 \\
6\end{array}$ & $\begin{array}{l}0 \\
2\end{array}$ & $\begin{array}{l}2 \\
6\end{array}$ & $\begin{array}{l}2 \\
6\end{array}$ & $\begin{array}{l}1 \\
1\end{array}$ & $\begin{array}{r}5 \\
15\end{array}$ & $\begin{array}{l}5 \\
10\end{array}$ & $\begin{array}{l}5 \\
0\end{array}$ & $\overline{2}$ & 5 & $\overline{3}$ & 4 & $\overline{1}$ \\
\hline
\end{tabular}

Both signer and non-signer groups represent convenience samples with the

\footnotetext{
${ }^{3}$ The tokens were not randomized. While there was no obvious patterning in the data due to nonrandomization, presentation order is a lurking variable. Phrase references match the presentation order, e.g. "phrase 3 " refers to the third token presented.
} 
signers accessed through acquaintances of the researcher and the non-signers primarily consisting of technical college students. Most of the signers are office workers living in Tokyo in their 30s and 40s, while the non-signers consist primarily of female students in their 20s. As a result of the population bias, age and gender are lurking variables in the data comparison between the signers and non-signers.

The signers have varied JSL acquisition experiences. Most have used JSL as their primary means of communication for over twenty years, and over half of the non-native signers started using JSL by the time they entered elementary school.

\subsection{Description of the Consultant Response Data Set}

The signing and non-signing consultant groups contrasted in about a third of their pen phrase ratings and rated about half of the pen phrase tokens similarly. The chart (2) below summarizes the standardized rating averages and standard deviations for the phrases for each group.

(2) Phrase Ratings Summary

\begin{tabular}{|l|l|r|r||r|r|r|r||r|r|}
\hline Ph\# & p diff & Non-signer Avg & SD & Avg z & SD & Signer Avg & SD & Avg z & \multicolumn{1}{l|}{ SD } \\
\hline 1 & $\mathbf{. 0 5 0 7}$ & 3.00 & 1.13 & 0.45 & 0.88 & 4.05 & 0.89 & 1.01 & 0.66 \\
2 & .2105 & 1.93 & 0.80 & -0.37 & 0.63 & 2.45 & 0.83 & -0.11 & 0.56 \\
3 & $\mathbf{. 0 6 5 7}$ & 1.07 & 0.26 & -0.97 & 0.15 & 1.65 & 0.88 & -0.72 & 0.55 \\
4 & .9727 & 3.20 & 0.94 & 0.61 & 0.69 & 3.55 & 0.76 & 0.62 & 0.45 \\
5 & .6694 & 1.20 & 0.56 & -0.84 & 0.43 & 1.35 & 0.75 & -0.77 & 0.62 \\
\hline 6 & .4479 & 1.60 & 0.91 & -0.57 & 0.59 & 1.50 & 0.61 & -0.71 & 0.40 \\
7 & $\mathbf{. 0 1 2 4}$ & 3.87 & 0.99 & 1.11 & 0.63 & 3.30 & 1.34 & 0.49 & 0.75 \\
8 & .3140 & 3.47 & 0.99 & 0.80 & 0.57 & 3.45 & 1.23 & 0.59 & 0.65 \\
9 & $\mathbf{. 0 0 6 8}$ & 2.87 & 0.83 & 0.35 & 0.48 & 3.90 & 0.97 & 0.85 & 0.54 \\
10 & .5776 & 1.20 & 0.68 & -0.86 & 0.43 & 1.25 & 0.44 & -0.94 & 0.34 \\
-10 & $\mathbf{. 0 0 2 9}$ & 2.40 & 0.74 & 0.05 & 0.48 & 3.45 & 1.19 & 0.66 & 0.64 \\
12 & .1659 & 3.53 & 0.99 & 0.87 & 0.69 & 4.35 & 0.81 & 1.16 & 0.46 \\
13 & .1179 & 1.27 & 0.70 & -0.81 & 0.43 & 1.10 & 0.31 & -1.01 & 0.25 \\
14 & .6279 & 1.00 & 0.00 & -1.03 & 0.19 & 1.05 & 0.39 & -1.07 & 0.26 \\
15 & .4096 & 4.40 & 0.74 & 1.56 & 0.56 & 4.60 & 0.60 & 1.42 & 0.43 \\
\hline 16 & $\mathbf{. 0 5 9 2}$ & 3.07 & 1.03 & 0.54 & 0.65 & 2.90 & 0.85 & 0.13 & 0.59 \\
17 & $\mathbf{. 0 3 8 2}$ & 2.33 & 0.90 & -0.01 & 0.58 & 1.90 & 1.07 & -0.46 & 0.66 \\
18 & .1184 & 3.73 & 0.70 & 1.06 & 0.50 & 3.85 & 0.88 & 0.79 & 0.49 \\
19 & .4808 & 1.13 & 0.52 & -0.92 & 0.31 & 1.30 & 0.73 & -0.83 & 0.43 \\
20 & .4052 & 1.00 & 0.00 & -1.03 & 0.19 & 1.00 & 0.32 & -1.09 & 0.27 \\
\hline
\end{tabular}

Averages and standard deviations for the raw ratings and standardized ratings 


\section{Johnny George}

both appear. ${ }^{4}$ The more a standardized average (Avg Z) is above zero, the more the consultants feel that the given phrase is a "more careful" or polite expression than the average expression. The more a standardized average is below zero, the more consultants feel that the given phrase is "less inhibited" or lower in politeness than the average expression. The "p-diff" column contains two-tailed ttest $\mathrm{p}$-scores that measure the difference between the signer and non-signer standardized rating averages. For example, phrase one has a p-diff of .0507, so the ratings given by the non-signers and the signers represent statistically significantly different sets of responses. Comparing signers and non-signers, seven of the twenty ratings averages have a $\mathrm{p}<.10$ indicating that for about a little over a third of the phrase rating averages the differences between signer and nonsigner responses are significant. Nine of the averages have large p-scores of $\mathrm{p}>.30$, showing great overlap between the response sets of both the signers and non-signers. Phrase rankings indexed with feature descriptions were then arranged by rank from highest to lowest standardized averages for the signer and nonsigner groups to produce the feature chart (3) below.

(3) The Feature Chart

\begin{tabular}{|c|c|c|c|c|c|c|c|c|c|c|c|c|c|c|c|c|c|c|}
\hline \multicolumn{10}{|c|}{ NON-SIGNERS } & \multicolumn{9}{|c|}{ SIGNERS } \\
\hline $\mathbf{E}$ & $\mathbf{K}$ & 0 & $\# \mathbf{N}$ & $\mathbf{N \#}$ & $T$ & $\mathbf{S}$ & $\mathrm{H}$ & Phra se \# & Rnk & Phrase \# & $\mathrm{H}$ & $\mathrm{S}$ & $\mathrm{T}$ & $\mathbf{N \#}$ & $\# \mathbf{N}$ & 0 & $\mathbf{K}$ & $\mathbf{E}$ \\
\hline $\bar{E}$ & & $\mathrm{O}$ & $\# \mathrm{~N}$ & $\mathrm{~N} \#$ & 55 & $\bar{C}$ & $\bar{F}$ & $15_{(1.56) \text { 요 }}$ & 1 & $15_{(1.42) \text {. . }}$ & $\bar{F}$ & $\mathrm{C}$ & 55 & $\mathrm{~N} \#$ & $\# \mathrm{~N}$ & $\mathrm{O}$ & & $\bar{E}$ \\
\hline & $\mathrm{K}$ & $\mathrm{O}$ & $\# \mathrm{~N}$ & $\mathrm{~N} \#$ & 38 & c & $\mathrm{F}$ & 7 (1.11) 38 & 2 & $12_{(1.16) 23}$ & $\mathrm{~F}$ & $\mathrm{C}$ & 64 & $\mathrm{~N} \#$ & $\# \mathrm{~N}$ & $\mathrm{O}$ & $\mathrm{K}$ & \\
\hline$E$ & & $\mathrm{O}$ & $\# \mathrm{~N}$ & $\mathrm{~N} \#$ & 52 & $\mathrm{C}$ & $\mathrm{F}$ & $18_{(1.05) .25}$ & 3 & 1 (1.01).24 & F & $\mathrm{C}$ & 63 & $\mathrm{~N} \#$ & & $\mathrm{O}$ & $\mathrm{K}$ & $E$ \\
\hline & $\mathrm{K}$ & $\mathrm{O}$ & $\# \mathrm{~N}$ & $\mathrm{~N} \#$ & 64 & $\mathrm{C}$ & $\mathrm{F}$ & $12_{(0.57) .36}$ & 4 & 9 (0.85) 37 & $\mathrm{~F}$ & $\mathrm{C}$ & 40 & $\mathrm{~N} \#$ & & $\mathrm{O}$ & $\mathrm{K}$ & \\
\hline & & $\mathrm{O}$ & $\# \mathrm{~N}$ & $\mathrm{~N} \#$ & 48 & $\mathrm{C}$ & $\mathrm{F}$ & $8(0.50) .21$ & 5 & $18_{(0.79) .19}$ & F & $\mathrm{C}$ & 52 & $\mathrm{~N} \#$ & $\# \mathrm{~N}$ & $\mathrm{O}$ & & $E$ \\
\hline & $\mathrm{K}$ & $\mathrm{O}$ & $\# \mathrm{~N}$ & $\mathrm{~N} \#$ & 43 & c & F & $4(0.61) .41$ & 6 & $11_{(0.66) .43}$ & F & c & 50 & $\mathrm{~N} \#$ & & & $\mathrm{~K}$ & \\
\hline & & $\mathrm{O}$ & $\# \mathrm{~N}$ & $\mathrm{~N} \#$ & 43 & $\mathrm{C}$ & $\mathrm{F}$ & $16_{(0.54) .38}$ & 7 & $4 \quad(0.62) .43$ & $\mathrm{~F}$ & c & 43 & $\mathrm{~N} \#$ & $\# \mathrm{~N}$ & $\mathrm{O}$ & $\mathrm{K}$ & \\
\hline$E$ & $\mathrm{~K}$ & $\mathrm{O}$ & & $\mathrm{N} \#$ & 63 & $\mathrm{C}$ & F & 1 (0.45) 37 & 8 & 8 (0.59) 32 & F & $\mathrm{C}$ & 48 & $\mathrm{~N} \#$ & $\# \mathrm{~N}$ & $\mathrm{O}$ & & \\
\hline & $\mathrm{K}$ & $\mathrm{O}$ & & $\mathrm{N} \#$ & 40 & $\mathrm{C}$ & $\mathrm{F}$ & 9 (0.35) & 9 & 7 (0.49) 207 & $\mathrm{~F}$ & c & 38 & $\mathrm{~N} \#$ & $\# \mathrm{~N}$ & $\mathrm{O}$ & $\mathrm{K}$ & \\
\hline & $\mathrm{K}$ & & & $\mathrm{N} \#$ & 50 & $\mathrm{c}$ & $\mathrm{F}$ & $11_{(0.05) .37}$ & 10 & $16_{(0.13) .09}$ & $\mathrm{~F}$ & $\mathrm{C}$ & 43 & $\mathrm{~N} \#$ & $\# \mathrm{~N}$ & $\mathrm{O}$ & & \\
\hline E & & $\mathrm{O}$ & & $\mathrm{N} \#$ & 40 & P & F & $17(-0.01) .08$ & 11 & $2(0.11) .04$ & $\mathrm{~F}$ & $\mathrm{c}$ & 30 & & & $\mathrm{O}$ & $\mathrm{K}$ & $E$ \\
\hline E & $\mathrm{K}$ & 0 & & & 30 & $\mathrm{c}$ & F & $2 \quad(-0.37) .21$ & 12 & $17(-0.45) .09$ & $\mathrm{~F}$ & $\mathrm{P}$ & 40 & $\mathrm{~N} \#$ & & $\mathrm{O}$ & & $E$ \\
\hline & & 0 & & & 30 & P & & $6(-0.57) \underline{.08}$ & 13 & $6 \quad(0.71) \underline{47}$ & & $P$ & 30 & & & 0 & & \\
\hline & & & & & 38 & P & $\mathrm{U}$ & $13_{(-0.81) .39}$ & 14 & 3 (-0.72) 41 & & $P$ & 23 & & & 0 & & E \\
\hline & & & & & 26 & P & & $5 \quad(-0.54) .43$ & 15 & 5 (-0.77) 32 & & $P$ & 26 & & & & & \\
\hline & $\begin{array}{l}\text { hea } \\
\text { ign }\end{array}$ & po & & cente & ward & & $\begin{array}{l}=\mathrm{N} \\
=k a n \\
=\text { chi } \\
\text { sper }\end{array}$ & $\begin{array}{l}\text { co-occurs w } \\
\text { aimasen Oे } \\
\text { up }= \\
\text { pheral } \mathrm{T}=\mathrm{y}\end{array}$ & nÓ & $\begin{array}{l}\text { In in utteran } \\
\text { indE } O \\
\text { lon-standard } \\
\text { in } 100 \text { ths of }\end{array}$ & & & $\begin{array}{l}\mathrm{AN}=1 \\
\mathrm{E}=\mathrm{Fa} \\
15\end{array}$ & $\begin{array}{l}c 0-0 \\
\text { ial N } \\
\text { 5) } 0 .=\end{array}$ & $\begin{array}{l}\text { curs } \\
\text { MS } \\
\text { hras }\end{array}$ & & sign & \\
\hline
\end{tabular}

\footnotetext{
${ }^{4}$ The standardized averages (Avg $\mathrm{z}$ ) are based on z-scores: A consultant $\mathrm{z}$-score=(Individual rating-Avg of consultant ratings)/sd of consultant ratings. The standardized scores tend to lower the sd among consultants' ratings as differences in subjective weights are minimized.
} 


\subsection{The Feature Chart}

The feature chart (3) lists 15 of the phrases in ranked order indexed with sign features from the Pen Study. ${ }^{5}$ Each row represents a single pen request phrase labeled by features. The features selected were chosen on the basis of relevance to marking politeness as described in the literature. The table shows the features of the phrases ordered by average rankings for the non-signers on the left and the signers on the right. The average standardized rank score appears in parentheses to the right of each phrase number. In underlined subscript label pairs of rankings with p-scores from one-tailed matched pairs t-tests that allow comparison between the differences in averages of consecutive rankings. For example, the non-signers' $11^{\text {th }}$ ranked phrase 17 has a p-score of .08 . The p-score indicates that for the t-test with the alternative hypothesis, "the average rank of phrase 17 is greater than the average rank of phrase 2 " that $\mathrm{p}<.10$, therefore the difference in averages is statistically significant. Three specific examples follow that explain the chart in more detail.

\subsection{Three Pen Request Phrases}

The schematization of the politeness features of phrase 12 below represents a pen request that both signers and non-signers ranked high in terms of polite register.

(4) Phrase 12 with features [F C 64 N\# \#N O K]

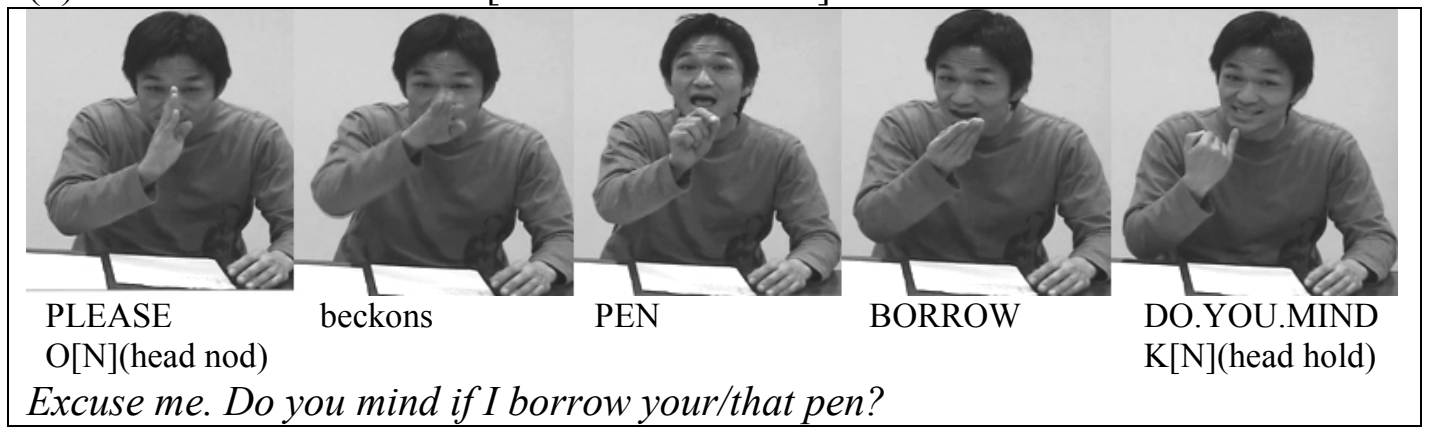

The sign for 'please' $(\mathrm{O})$ co-occurs with a head nod $(\# \mathrm{~N})$, and the phrase final sign 'do you mind' $(\mathrm{K})$ co-occurs with a head hold $(\mathrm{N} \#) .{ }^{6}$ These features appear in four columns representing phrase 12 in the feature chart (3)-the columns $(\mathrm{O})$,

\footnotetext{
${ }^{5}$ The top 15 of the 20 phrases are represented since these expressions cover most of the feature contrasts.

${ }^{6}(\mathrm{~N})$ marks both head nods and head holds as described by Ichida (2005b). The sign "please" (O) typically occurs with a head nod and the sign "do you mind" (K) typically collocates with a head hold. The two types of head movement tend to class together, so to simplify this paper I will not distinguish the two in the final analysis.
} 
$(\mathrm{K}),(\mathrm{N} \#)$, and $(\# \mathrm{~N})$. (F) indicates that the signer has his head in a chin forward position (Ichida 2005c), and (C) means that he centers his signing within the boundary formed by his chest rather than pushing signs out to the periphery of the signing space. The number $(\mathrm{T}=64)$ represents the signing rate $(\mathrm{T})$ measured as the amount of time to initiate and form a manual sign in hundredths of a second. In this expression, the signer averages about one and a half signs a second, a relatively slow rate.

The second example shows stills from phrase 5, an expression rated low in terms of polite register by both non-signers and signers.

(5) Phrase 5 with features [P 26]

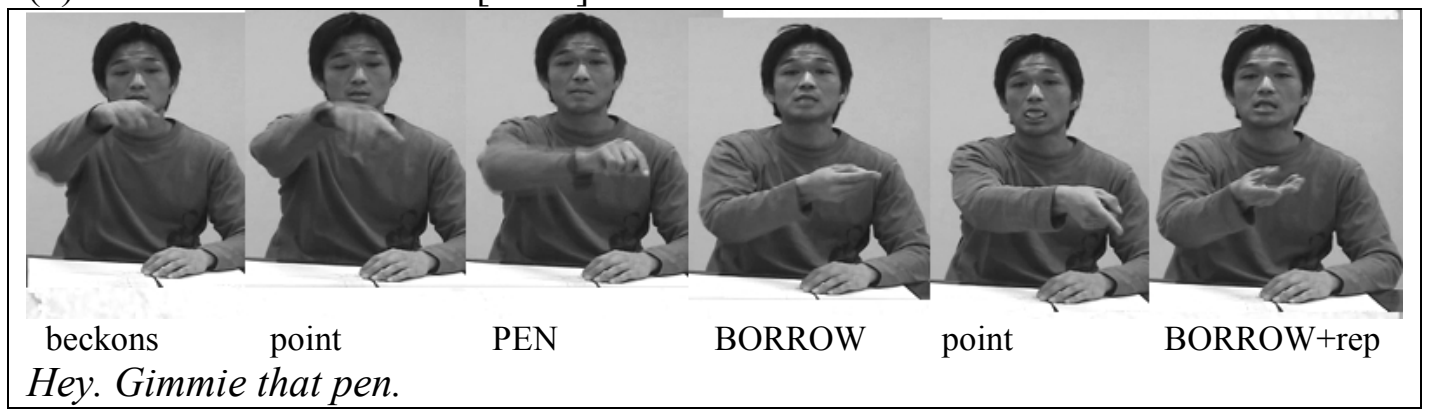

Phrase 5 has far less feature marking than phrase 12 above. The signer maintains a neutral chin position and does not use any lexical polite forms such as 'please' $(\mathrm{O})$ or 'do you mind' $(\mathrm{K})$. The utilized signing space is wider as his arm fully extends into the space in front of him and beyond shoulders' width. He signs about four signs a second $(\mathrm{T}=26)$, a much faster rate than in the previous expression. The final sign BORROW gets repeated a number of times.

Phrase 1 receives contrastive rating averages with the signers rating the phrase high and non-signers rating it low.

(6) Phrase 1 with features [F C 63 N\# O K E]

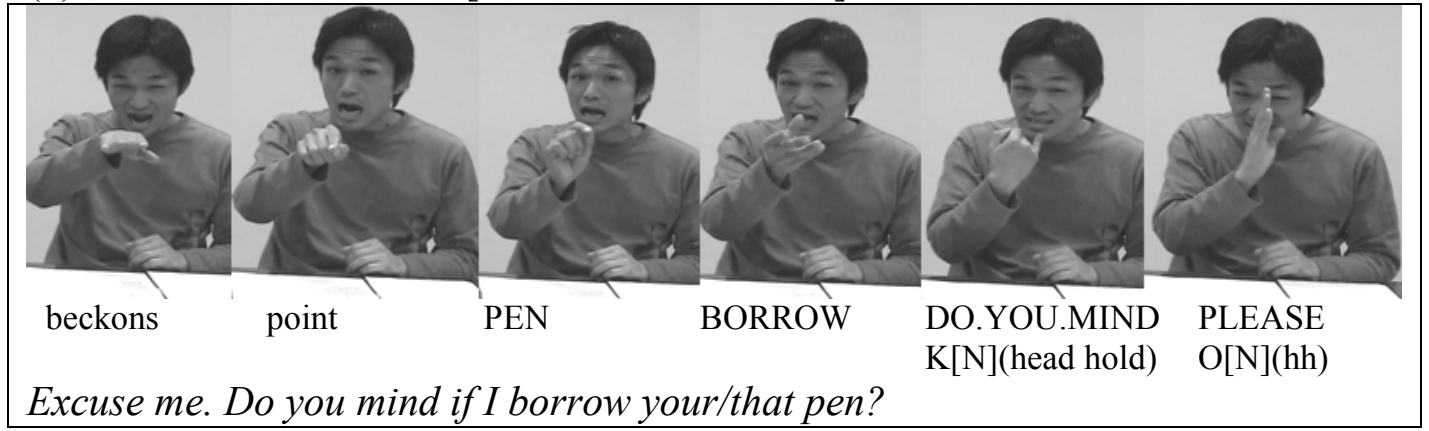

Phrase 1 contains many of the same politeness markers as phrase 12 . The signer puts his head in a forward position (F) and keeps the signing centralized (C). The rate of signing is the same as in phrase 12 at about one and a half words 


\section{Universals in the Visual Kinesthetic Modality}

a second $(\mathrm{T}=63)$. This phrase includes the lexical signs 'please' $(\mathrm{O})$ and 'do you mind' and both co-occur with a head hold. The final word 'please' $(O)$ involves a lower positioning of the head and occurs with a head hold representing a phrase ending final nod (N\#). The signer's face also evidences a polite grimace $(\mathrm{E})^{7}$.

\subsection{Observations about the Request Phrase Data}

The phrases above show that signers and non-signers rate expressions with particular prosodic characteristics as more polite. Rate of signing, centralization of signs in the signing space, head position and use of the polite lexical items all seem to potentially affect how polite an expression is perceived. In the examples above a number of the features marking politeness seem to conform with observations in the literature while others don't.

\subsubsection{Shared Judgments between Signers and Non-Signers}

A slower rate of signing that results in less assimilation (Cokely and Baker-Shenk 1980, Liddell and Johnson 1989[1985], Ross and Berkowitz 2008, Zimmer 1989) appears to correlate with a greater degree of polite expression. Phrase 1 appears to contradict this claim for the non-signers but in a linear regression account the rate of signing against average sign ratings shows a statistically significant correlation with faster signed words correlating with lower ratings. Signers had an $\mathrm{r}^{2}$ of 0.635 $(\mathrm{p}<.001)$, and non-signers $0.5557(\mathrm{p}<.001)$, accounting for about $56 \sim 64 \%$ of the variance. Since ASL and JSL signers rate faster signs as lower in register, the rate of signing may serve as a register marker salient crosslinguistically. Such a result couples with the fact that non-signers also respond to this same cue and share the same intuitions as signers in this study.

In contrast to the claim of Zimmer (1989) the use of a smaller signing space occurred more commonly in the more highly ranked signs for both signers and non-signers in the study, as can be seen on the feature chart (3). The work of Uyechi (1996) offers some insight to the contradiction of the findings of Zimmer. Uyechi notes that the nature of discourse determines the appropriate signing size space to use, keeping the signs otherwise proportionately the same-in the case of a protest for instance, producing enormous signs visible from the largest distance possible is apropos. The size of signing space represents a visibility or "loudness" contrast, so it is likely that in the Zimmer cases, the signer had to present to an audience in a larger presentation space for the formal context, an academic lecture as opposed to the more confined spaces of the less formal contexts, a television set and a small informal talk setting. If we examine signing space size in light of Uyechi's observation, just as one may possibly assume that reducing the voice

\footnotetext{
${ }^{7} \mathrm{E}$ in the chart represents any marked facial expression, not just the polite grimace. Phrase 15 has a polite grimace frown and phrase 18 has a polite grimace.
} 
can make speech more polite, utilizing a smaller signing space can create relatively more polite sign. Examples from other languages are needed to see how the use of signing space works crosslinguistically.

Although not discussed in the three example phrases above, the top ranked phrase for both signers and non-signers consisted of the polite grimace frown (Roush 2007[1999], Hoza 2007). The average ranking of the first phrase rated significantly higher than the second ranked phrase for both groups, and the polite grimace frown feature stands out as the contrastive feature relative to other phrases. This feature appears in only one token, so more evidence could lend support to the crosslinguistic salience of the polite grimace frown.

The crosslinguistic salience of particular facial NMS may be attributed to the 'frequency code.' Ohala (1994) uses data from phonetic studies coupled with ethological principles to discuss how a lower fundamental frequency $\left(\mathrm{F}_{0}\right)$ or pitch vocalization signals a larger sized body in contrast to a higher $F_{0}$ vocalization which indicates a small body. Ohala explains that across species, animals vocalize using a lower $F_{0}$ when threatening and use higher $F_{0}$ vocalizations when submissive since the use of such vocalizations is grounded in the sound to size association. Ohala dubs the sound to size association the 'frequency code.' Ohala suggests that the 'frequency code' may account for the smile as a non-threatening facial display in contrast to what he calls the "o-face" used with threat signals. The smile has an association with a higher $F_{0}$ in contrast to the "o-face" that appears to correlate with a lower $\mathrm{F}_{0}$. These traits inherited by humans eventually became ritualized and remain salient communicative markers across languages. As in the relation between pitch or facial expression and body size, some crosslinguistically recognized facial NMS might also derive from the 'frequency code' effect.

The forward head position (F) appears to serve as a politeness marker for both signers and non-signers as phrases with this feature rate at the top of scale of politeness ranking. Ichida (2005c) does not account for this type of politeness marking. Since the head forward position also involves lowering of the head, there may be some association with humility for this position. Further evidence is needed to elucidate the function of this feature.

\subsubsection{Judgment Contrasts between Signers and Non-Signers}

One way in which the judgments of the signers and non-signers pattern differently is in the response to the appearance of signs accompanied by head nods at the beginnings and ends of phrases. For the non-signers, any phrase beginning with a nod $(\# \mathrm{~N})$, all paired with the sign for please $(\mathrm{O})$, outscore any phrase that does not. The same is not true for signers who appear to consider the content of the entire expression - as seen by the fact that many of the top ranked expressions of the signers do not contain an initial please with a nod. Phrase 1 illustrates the 


\section{Universals in the Visual Kinesthetic Modality}

difference in judgment between signers and non-signers for such a phrase. The two major distinctions between phrase 1 and phrase 12 is the phrase initial (O) with a nod and the polite grimace.

The reason that non-signers find the sign please with a nod particularly salient is that these features resemble emblems or conventionalized communicative gestures (McNeill 2005) in Japanese society. The sign for please resembles the hand-prow emblem which consists of raising a flat hand at the head level with the fingers pointed up and the plane of the palm perpendicular to the plane of the chest. The person making the emblem moves his or her hand back-and-forth while moving through a crowded space. This gesture signals that the user of the emblem will pass through, and bystanders can then provide more space for the person's passage. Like a language expression, users learn the emblem through normal, everyday life experience. Deaf and hearing people who have sight have equal access to emblematic forms, so both groups have an equally shared cultural communication system vis-à-vis emblems. In addition the nod resembles another Japanese emblem, the bow. Bowing as a greeting represents a well-known emblem in Japan - its use is widespread and completely conventionalized in all regions of Japan.

Non-signers have to pick cues to distinguish between the politeness levels of the expressions, and the culturally shared emblems provide a means for them to make politeness evaluations. The non-signers may be biased in their judgment of signs that resemble cultural emblems.

In contrast, the JSL sign 'do you mind' $(\mathrm{K})$ appears to serve as a more salient marker for politeness for the signers as the phrases with that feature tend to cluster near the top.

\section{Conclusion}

Consultants identified the phrases consisting of prosodic markers of politeness as relatively more polite and demonstrate that JSL relies heavily on prosody for politeness marking. Non-manual signal (NMS) features such as facial expression, size of signing space, head position and rate of signing signal politeness register contrasts.

Signers and non-signers have closely shared communicative practices evolving from their shared social context. So non-signers' have the capacity to access information from the sign modality due to shared visual-kinesthetic communicative practice. Shared social context means that a relationship exists between the sign language of signers and their contact spoken language(s). It is not a question of whether signers are use spoken language cues, rather, it is a result of languages emerging from the same social spaces.

Non-signers can decode parts of the sign signal sometimes; however, not necessarily with the same understanding as signers. Social communicative 
Johnny George

practice overlaps but takes on different garbs for each group.

There appear to be some cross-sign intelligibility for particular types of prosodic features. The study found that JSL had some similar register marking features as ASL including the polite grimace frown and rate of signing. More comparative work across sign languages will undoubtedly uncover a number of crosslinguistically salient communicative cues.

\section{References}

Brown, Penelope, and Stephen Levinson. 1987. Politeness: Some Universals in Language Usage, Studies in Interactional Sociolinguistics; 4. Cambridge [Cambridgeshire]; New York: Cambridge University Press.

Cokely, Dennis, and Charlotte Lee Baker-Shenk. 1980. American Sign Language: a Student Text. Silver Spring, Md.: T.J. Publishers.

Hill, Beverly, Sachiko Ide, Shoko Ikuta, Akiko Kawasaki, and Tsunao Ogino. 1986. Universals of Linguistic Politeness: Quantitative Evidence from Japanese and American English. Journal of Pragmatics:347-71.

Hoza, Jack. 2007. It's Not What You Sign, It's How You Sign It: Politeness in American Sign Language. Washington D.C.: Gallaudet University Press.

Ichida, Yasuhiro. 2005a. Sign Linguistics Series (8): Head position and Mouth Shape--Japanese Sign Language Grammar (4). [Perception Verbs, Reason Verbs, NMS Adverbs]. Gekkan Gengo 34 (8):92-99.

Ichida, Yasuhiro. 2005b. Sign Linguistics Series (9): Head Movement, Head Position and Facial Expression--Japanese Sign Language Grammar (5). [Sentence Type and Subordinate Clauses]. Geppan Gengo 34 (9):94-101.

Ichida, Yasuhiro. 2005c. Sign Linguistics Series (12): Iconicity and MetaphorJSL Lexical Organization. Gekkan Gengo 34 (12):88-96.

Liddell, Scott K., and Robert E. Johnson. 1989 [1985]. American Sign Language: Phonological Base. Sign Language Studies 64:197-277.

McNeill, David. 1992. Hand And Mind: What Gestures Reveal About Thought. Chicago: University of Chicago Press.

Ohala, John. 1994. The Frequency Code Underlies the Sound-Symbolic Use of Voice Pitch. In Sound Symbolism, edited by L. Hinton, J. Nichols and J. Ohala. 
Cambridge: Cambridge University Press.

Ross, Linda L., and Marla C. Berkowitz. 2008. Academic ASL: It Looks Like English, But It Isn't. Paper read at Teh PEPNet 2008 Conference: Putting the Pieces Together, at Columbus, $\mathrm{OH}$.

Roush, Daniel. 2007[1999]. Indirectness Strategies in American Sign Language Requests and Refusals: Deconstructing the Deaf-as-direct Stereotype. In Translation, Sociolinguistic, and Consumer Issues in Interpreting, edited by M. Metzger and E. Fleetwood. Washington, D.C.: Gallaudet University Press.

Sandler, Wendy. 2006. Sign Language and Linguistic Universals. Cambridge, UK; New York: Cambridge University Press.

Uyechi, Linda Ann N. 1996. The Geometry of Visual Phonology, Dissertations in Linguistics Series: Center for the Study of Language and Information.

Zimmer, June. 1989. Toward a Description of Register Variation in American Sign Language. In The Sociolinguistics of the Deaf Community, edited by C. Lucas. San Diego: Academic Press.

Johnny George

The University of Tokyo

Department of English Language College of Arts and Sciences

Komaba 3-8-1, Meguro-ku

Tokyo 153-8902

jeg.727@gmail.com 